Garcia, F.O.; Neiman, Z.; Prado, B.H.S. Planejamento de uma Trilha Interpretativa na Estação Ecológica de Angatuba (SP). Revista Brasileira de Ecoturismo, São Paulo, v.4, n.3, 2011, pp.323-344.

\title{
Planejamento de uma Trilha Interpretativa na Estação Ecológica de Angatuba (SP)
}

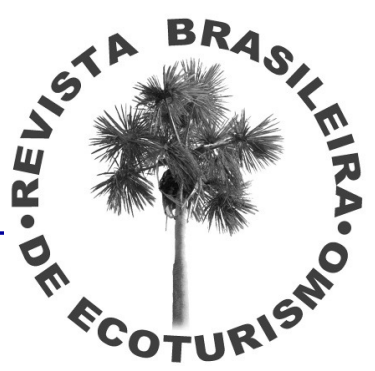

\section{Francini de Oliveira Garcia, Zysman Neiman, Bárbara Heliodora Soares do Prado}

\begin{abstract}
RESUMO
A Estação Ecológica de Angatuba, situada nos municípios de Angatuba e Guareí, Estado de São Paulo, uma Unidade de Conservação de Proteção Integral administrada pelo Instituto Florestal, foi criada em 1985. O Plano de Manejo da Unidade foi aprovado em 2009 pelo Conselho Estadual do Meio Ambiente (CONSEMA) e já possui recursos financeiros para sua implantação, provenientes de compensação ambiental. A implantação de Trilhas Interpretativas é uma das ações previstas no Programa de Educação Ambiental da Unidade, assim, esse trabalho teve como objetivo realizar o planejamento de uma Trilha Interpretativa, através do Método IAPI (Indicadores de Atratividade de Pontos Interpretativos). Foram selecionados 30 potenciais pontos de interpretação e somente 13 pontos entraram no roteiro da trilha, sendo dois pontos de descanso. Elaborou-se um esboço do Roteiro de Interpretação Ambiental, com o propósito de esse ser desenvolvido de forma participativa nas oficinas de Educação Ambiental. Foram propostas placas de interpretação para serem colocadas em alguns pontos no percurso da trilha.
\end{abstract}

PALAVRAS-CHAVE: Unidades de Conservação; Estação Ecológica de Angatuba; Interpretação Ambiental.

Planning of an Interpretative Track in the Estação Ecológica de Angatuba (SP, Brazil)

\section{ABSTRACT}

The Estação Ecológica de Angatuba, located in the municipalities of Angatuba e Guareí, São Paulo state, a Protected Area of Integral Protection managed by the Instituto Florestal, was established in 1985 . The Management Plan was approved in 2009 by the Conselho Estadual de Meio Ambiente (CONSEMA) and already has financial resources for its implementation, obtained by environmental compensation. Deploying Interpretive Track is one of the actions foreseen in the Environmental Education Program, so this study was aimed the planning of an Interpretative Track. Through the method IAPI (Attractiveness Indicators of the Interpretive Points ), were selected 30 potential points of interpretation, and only 13 points came in the itinerary of the track, two these points are resting points. Was prepared itinerary's draft of Environmental Interpretation, the purpose of this being developed in participatory workshops of Environmental Education. Interpretation boards have been proposed to be placed at certain points in the route of the track.

KEYWORDS: Protected Areas; Estação Ecológica de Angatuba; Environmental Interpretation. 


\section{Introdução}

As Unidades de Conservação são consideradas a pedra angular da conservação in situ, sendo essenciais na preservação da diversidade biológica, do estoque genético representado pelos organismos vivos e na manutenção dos serviços ecológicos. São áreas instituídas pelo Poder Público ou Privado com a finalidade de proteger a fauna, flora, recursos hídricos, solos, paisagens e processos ecológicos pertinentes aos ecossistemas naturais, além de preservar o patrimônio associado às manifestações culturais dos brasileiros. Representam a condição básica para a conservação e perpetuação da diversidade biológica, conciliando a manutenção dos modos de vida das culturas tradicionais com a proteção da natureza (OLIVEIRA, 2009).

De acordo com Oliveira (2009), a criação e manutenção de Unidades de Conservação, assim como o ordenamento de suas respectivas zonas de amortecimento constituem-se um dos mais eficazes instrumentos de planejamento territorial ambiental.

Para Araújo (2007) as Unidades de Conservação devem ser vistas como organizações - sistemas, as quais fornecem bens e serviços como recursos naturais, recreação ambiental, ambiente para pesquisas e manutenção dos serviços ecossistêmicos aos beneficiados, que são a sociedade em geral, o governo, as comunidades locais, o órgão gestor, as prefeituras, os pesquisadores e os turistas (quando houver). Esse sistema é composto pelo subsistema social: funcionários; e subsistema técnico: tarefas, instalações físicas, equipamentos e recursos.

Ultimamente, tem se dado o devido valor às UCs pelo papel que desempenham no fornecimento de serviços ambientais, como a produção de oxigênio pelas plantas, a capacidade de produção de água e equilíbrio do ciclo hidrológico, fertilidade do solo, vitalidade dos ecossistemas, a paisagem, o equilíbrio climático e o conforto térmico (OLIVEIRA, 2009).

Segundo o Sistema Nacional de Unidades de Conservação (SNUC), as Estações Ecológicas (EsEc) possuem como objetivo a preservação da natureza e a realização de pesquisas científicas, sendo que são de posse e domínio públicos; a visitação pública só pode se realizar quando com objetivo educacional; as pesquisas científicas dependem de uma autorização prévia do órgão gestor responsável e estão sujeitas a restrições por este estabelecidas; as alterações dos ecossistemas são permitidas somente no caso de restauração de ecossistemas modificados, manejo de espécies com finalidade de preservar a diversidade biológica, coleta de componentes dos ecossistemas com finalidades científicas e pesquisa científica que causem algum impacto sobre o ambiente.

Esse artigo apresenta os resultados do trabalho de planejamento de uma Trilha Interpretativa na Estação Ecológica de Angatuba, para qual selecionou-se os Pontos de Interpretação e descanso; estabeleceu-se o esboço do Roteiro de Interpretação Ambiental; e eleborou-se o design de possíveis placas de interpretação a serem colocadas no seu percurso. 


\section{Interpretação Ambiental e Trilhas Interpretativas}

A interpretação ambiental não deve ser confundida com educação ambiental, pois ela em si não é considerada educação ambiental, mas um instrumento de comunicação que proporciona conexões emocionais e intelectuais entre os interesses dos ouvintes e os significados inerentes aos recursos naturais (VASCONCELLOS, 2006). Ela é considerada uma ferramenta para a Educação Ambiental (NEIMAN; LEITE; PODADERA, 2009). Podese dizer que a interpretação ambiental não trabalha apenas com informações ecológicas, como na educação ambiental, mas com os sentimentos e emoções das pessoas, fazendo com que essas tenham uma nova percepção do ambiente natural.

A interpretação ambiental é uma ferramenta estimulante que faz as pessoas compreenderem o seu entorno ecológico através da transformação da linguagem da natureza para a linguagem das pessoas, o que proporciona a descoberta de um mundo que nunca tinham percebido antes (VASCONCELLOS, 2006).

A história da interpretação ambiental está intimamente ligada aos parques norteamericanos que no final do século XIX já estavam legalmente protegidos e contavam com os chamados naturalistas. Mills foi um naturalista e o primeiro a utilizar o termo "interpretação", seguido por Tilden (1977) (apud VASCONCELLOS, 2006, p. 23) que estabeleceu a sua conceituação:

[...] a interpretação é uma atividade educativa que aspira revelar os significados e as relações existentes no ambiente, por meio de objetos originais, através de experimentos de primeira mão e meios ilustrativos, em vez de simplesmente comunicar informação literal.

Assim como Tilden (1977), Chagas (2006), Neiman e Rabinovici (2008), Soares (2004) e Vasconcellos (2006) acreditam que os cinco sentidos devem ser utilizados na interpretação ambiental para estimular a percepção da natureza pelo indivíduo através da sensibilização ambiental, que é considerada um dos principais pré-requisitos para construir o comportamento ecologicamente responsável (SENICIATO; CAVASSAN, 2004).

O trabalho realizado por Seniciato e Cavassan (2004) mostrou que o contato direto com ambientes naturais faz surgir emoções e sensações que levam ao prazer e encantamento com a natureza. Neiman e Rabinovici (2002) afirmam que é necessário despertar nas experiências com a natureza sentimentos que impliquem em vínculo do indivíduo com o ambiente, despertando uma percepção subjetiva de sua beleza, proporcionando a sensibilização através da experiência direta, que de acordo com estudiosos, está relacionada à interpretação ambiental. Assim, atividades desenvolvidas diretamente na natureza contribuem definitivamente para consolidação da sensibilidade ambiental (SOARES, 2004).

A interpretação ambiental através da sensibilização do contato direto com ambientes naturais é responsável pelo despertar do comportamento pró-ambiente do indivíduo, levando-o a adquirir novos conceitos quanto à relação homem-natureza e a agir em favor da conservação ambiental (LOUREIRO, 2002 apud CHAGAS, 2006; NEIMAN; RABINOVICI, 2008; NEIMAN; LEITE; PODADERA, 2009). Para Guimarães (2007, p. 74), "a interpretação ambiental é culturalmente condicionada, considerados os significados e 
as configurações das imagens de mundo vivido, nos aspectos pertinentes aos sentimentos de biofilia, topofilia e topofobia".

De acordo com Andrade (2007) e Salvatti (2006 apud SANTOS, 2007) uma trilha não pode ser considerada apenas um caminho, ela é o ambiente onde a caminhada se desenvolve com o objetivo de aproximar o visitante ao ambiente natural, possibilitando estimular o interesse por áreas naturais e locais preservados através de sinalizações ou de recursos interpretativos. Assim, uma trilha interpretativa pode ser considerada um meio para o desenvolvimento da interpretação ambiental (ZANIN, 2006), sendo um espaço que pode ser compreendido e sentido pelo visitante (NEIMAN; LEITE; PODADERA, 2009).

Segundo Vasconcellos (2006) a trilha interpretativa é considerada uma das possibilidades de proporcionar aos participantes uma discussão da ideia de fazer parte e ser responsável pela preservação e conservação da natureza. Além de visarem a transmissão de conhecimento possuem como principal objetivo propiciar atividades que revelem significados e características do ambiente por meio do uso dos elementos originais, através da experiência direta e de meios ilustrativos.

As trilhas interpretativas proporcionam práticas cooperativas em grupos, socialização e conciliação das formas de conhecimento empírico e técnico-científico, colaborando efetivamente no desenvolvimento de ações conservacionistas. Ela favorece um conhecimento através de diálogos e da experiência direta (CHAGAS, 2006; GUIMARÃES, 2007).

Zanin (2006), afirma que ao percorrer uma trilha interpretativa há o descobrimento das limitações e possibilidades. Para Lima (1998) (apud GUIMARÃES, 1998, p. 41), "trilhas interpretativas são como espelhos posicionados estrategicamente para refletirem a paisagem interior na exterior" levando os indivíduos à percepção de que fazem parte da natureza, despertando novas concepções.

De acordo com Andrade e Rocha (2008) as trilhas podem ser classificadas quanto à sua função, forma e grau de dificuldade. Quanto à Função podem ser utilizadas para manutenção, fiscalização e gerenciamento em serviços administrativos ou para educação, recreação e estudo pelo público visitante. Nestes casos, podem ser divididas em trilhas de curta distância - até 2.500 m de extensão - chamadas trilhas de interpretação (natural trails) que possuem caráter recreativo e educativo com programação desenvolvida para interpretação ambiental; média distância - 2.500 m a 5.000 m; ou de longa distância acima de $5.000 \mathrm{~m}$ - (wilderness trails), as quais possuem somente caráter recreativo como viagens de travessia pela região. Ainda nessa classificação as trilhas podem ser subclassificadas quanto aos recursos de interpretação ambiental de duas maneiras: guiadas ou autoguiadas (ROCHA et al., 2006 apud ANDRADE; ROCHA, 2008). A primeira se caracteriza por ser realizada com acompanhamento de um guia tecnicamente capacitado para realizar a atividade de interpretação do ambiente; enquanto que a segunda se dá sem a presença do guia, onde as informações necessárias e os temas desenvolvidos são mostrados através de recursos visuais, gráficos e outros.

Quanto à Forma, as trilhas podem ser classificadas em: circulares, que permitem voltar ao ponto de partida sem repetir o percurso; oito, as quais prestam-se a áreas limitadas, pois aumentam a possibilidade de uso destas áreas; lineares, que conectam o caminho principal a algum destino, sendo as mais comuns e simples, apresentando as 
desvantagens do caminho de volta ser igual ao de ida e a possibilidade de se cruzar com outros visitantes; e atalho, as quais possuem o início e fim em diferentes pontos (ANDRADE; ROCHA, 2008).

O Quadro 1 mostra a classificação de trilhas dada por Andrade e Rocha (2008) quanto ao Grau de Dificuldade. Nessa classificação é relacionado o item (a) ao item (b), sendo uma característica da intensidade do percurso e o grau das atividades exercidas, respectivamente. A classificação final se dá da seguinte maneira: letra (grau) + número (intensidade).

Quadro 1: Classificação de trilhas quanto ao Grau de Dificuldade (ANDRADE; ROCHA. 2008).

\begin{tabular}{|c|c|c|}
\hline \multirow{3}{*}{ a) } & \multirow{3}{*}{ Graduação } & 1- Fácil \\
\hline & & 2- Moderada \\
\hline & & 3- Extenuante \\
\hline \multirow{5}{*}{\multicolumn{2}{|c|}{$\begin{array}{l}\text { b) Classificação das } \\
\text { atividades }\end{array}$}} & $\begin{array}{l}\text { Grau A: passeios que podem ser apreciados sem obrigatoriedade de } \\
\text { ter de desenvolver alguma atividade física. Não requer experiência } \\
\text { anterior. }\end{array}$ \\
\hline & & $\begin{array}{l}\text { Grau B: requer alguma atividade física; se for necessário pernoitar na } \\
\text { trilha, é recomendado (mas não exigido) experiência de camping. Em } \\
\text { geral, não é necessário carregar uma mochila pesada, mas se este for } \\
\text { o caso, adotar-se-á graduação B-3. }\end{array}$ \\
\hline & & $\begin{array}{l}\text { Grau C: requer condicionamento físico, pois as trilhas podem ser } \\
\text { longas, acidentadas e/ou cansativas. Em geral, envolve pernoite na } \\
\text { trilha. }\end{array}$ \\
\hline & & $\begin{array}{l}\text { Grau D: requer bom condicionamento fisico e experiência básica em } \\
\text { montanhismo: camping, caminhada em clima adverso, manuseio de } \\
\text { equipamentos. Pode exigir o fator altitude (acima de } 4.000 \mathrm{~m} \text { ). }\end{array}$ \\
\hline & & $\begin{array}{l}\text { Grau E: EXPEDIÇÃ̃O: a pessoa de vê ser capaz de desenvolver } \\
\text { intensa atividade física durante muitos dias em lugares de difícil } \\
\text { acesso. Ė necessária experiência comprovada em montanhismo. } \\
\text { Deve-se estar preparado para executar as mesmas tarefas dos guias: } \\
\text { cozinhar, montar barracas, etc. }\end{array}$ \\
\hline
\end{tabular}

No planejamento de uma trilha devem-se considerar fatores como solo, vegetação, fauna, recursos hídricos, visitantes e comunidade local, assim como estabelecer o objetivo da trilha, os elementos de interpretação e o público alvo. É necessário um amplo conhecimento do local para que se possa alcançar o objetivo da trilha e causar o mínimo de impacto possível (ANDRADE; ROCHA, 2008). 


\section{Estação Ecológica de Angatuba}

A localidade onde se encontra Estação Ecológica de Angatuba era uma antiga fazenda particular, chamada de Fazenda da Conquista pertencente a família Vieira de Moraes. Em 1965 a fazenda foi comprada pelo Governo do Estado de São Paulo, onde foi criada a Floresta Estadual de Angatuba em uma área de 2.590,15 ha. Somente em 1985 foi criada a Estação Ecológica de Angatuba nas áreas que não foram utilizadas para o reflorestamento pela Floresta Estadual de Angatuba.

Esta Unidade de Conservação de Proteção Integral preserva importante fragmento de vegetação natural, com vegetação de Cerrado, cerca de $25 \%$ da área, e uma significativa área de Floresta Estacional Semidecidual. Apresenta alta diversidade de espécies vegetais e faunística, sendo o habitat de diversas espécies da fauna brasileira que se encontram nas listas oficiais de espécies ameaçadas de extinção. $O$ fato de não haver Unidade de Conservação Federal no Estado de São Paulo que abranja o cerrado, faz da Estação Ecológica de Angatuba uma área significante para a preservação desse bioma.

Foi amostrada até o momento, a ocorrência de 713 espécies vegetais, das quais 15 constam da lista oficial de espécies ameaçadas do Estado de São Paulo, 26 espécies de mamíferos, sendo que 12 destas espécies constam da lista de espécies ameaçadas e 188 espécies de aves, das quais 05 são espécies ameaçadas.

Cabe ressaltar que o estado de conservação da Estação Ecológica de Angatuba, sua riqueza florística e diversidade de habitat são fatores que proporcionam a ocorrência e sobrevivência do mico-leão-preto (Leontopithecus chrysopygus), espécie de primata que foi dada como extinta, sendo redescoberta na década de 1970.

A Estação Ecológica de Angatuba é contígua a Floresta Estadual de Angatuba, uma unidade de experimentação florestal. Esse fator possibilita uma associação entre a conservação da natureza, pesquisa e produção florestal, conferindo uma gestão integrada das duas Unidades, a qual se baseia nos princípios da sustentabilidade e visa à melhor distribuição dos bens e serviços provenientes das florestas naturais e plantadas à comunidade do entorno da Unidade, que é composta em sua maioria por pequenos e médios proprietários de terras. Está situada na Depressão Periférica Paulista no subcompartimento denominado Depressão do Paranapanema, a qual é caracterizada em geral por relevos mais recortados e acidentados do tipo morretes alongados e espigões ou colinosos do tipo colinas médias.

O tipo climático é Cwa, com temperatura média no mês mais frio inferior a $18 \mathrm{C}$, e no mês mais quente superior a $22 \mathrm{C}$. As chuvas se concentram no verão, sendo que no inverno ocorrem as menores precipitações, que são inferiores aos $60 \mathrm{~mm}$.

Segundo Oliveira et. al. (1999) (apud MONTEIRO; PRADO, 2009), na região há predomínio de Latossolo Vermelho-Amarelo distrófico com textura média, o qual se associa ao Neossolo Quartzarênico órtico distrófico, ambos apresentam horizonte superficial $A$ do tipo moderado ocorrendo em relevo suave ondulado e plano. Também ocorrem Argissolo Vermelho-Amarelo distrófico de textura arenosa/média em relevo ondulado a forte ondulado e Argissolo Vermelho-Amarelo distrófico de textura média/ argilosa em relevo ondulado a suave ondulado. 
Além da vegetação do tipo Floresta Estacional Semidecidual Montana, Aluvial de Inundação temporária e Aluvial de Inundação Permanente há três fisionomias do Cerrado: Savana Florestada (Cerradão) Savana Arborizada (Cerrado sentido restrito) e Savana Gramíneo-lenhosa (Campo) (VELOSO; RANGEL FILHO; LIMA, 1991 apud MONTEIRO; PRADO, 2009).

A região da Estação Ecológica situa-se na bacia hidrográfica do Alto Paranapanema, na qual encontra-se o perímetro Botucatu da APA Corumbataí/Botucatu/ Tejupá (Decreto Estadual $n^{\circ} 20.960$, de 8 de junho de 1983), que abrange o município de Guareí e pequena porção do município de Angatuba. O rio Guareí faz limite com a Unidade e corre paralelamente ao rio Itapetininga em direção ao rio Paranapanema. Possui área de 1.394,15 ha e o acesso pode ser realizado pela Rodovia Raposo Tavares (SP 270) ou pela Rodovia Castelo Branco (SP 280).

Como na maioria das Unidades de Conservação do Brasil a EsEc de Angatuba apresenta espécies de flora exóticas e invasoras. A espécie arbórea invasora Pinus elliottii é a mais evidente na Unidade, estando presente em boa parte das áreas savânicas. Ações de curto prazo são necessárias para a eliminação dessa espécie exótica. Também ocorrem a invasão de gramíneas africanas Urochloa decumbens (braquiara) e Melinis minutiflora (capim-gordura), além das Samambaias ruderais Pteridium aquilinum e Dicranopterys sp., que impedem a sucessão secundaria das plantas nativas, e o Hedychium coronarium (lírio-do-brejo), que impede o estabelecimento de plantas nativas. A caça de animais silvestres e a presença de gado da vizinhança são fatores considerados de ameaça à conservação da Unidade.

A estrada municipal Ang. 230, que interliga Angatuba a Guareí cortando a EsEc de Angatuba, também é outro fator de ameaça pelo fato de ser um vetor de entrada de pessoas não autorizadas, dificultando a fiscalização; uma barreira ecológica para migração de algumas espécies, o que é necessário para mantê-las viáveis a longo prazo; e proporcionar a morte de animais por atropelamento.

A prevenção do fogo é realizada através da estratégia de aceiramento em todo o perímetro da Unidade e pela vigilância em uma torre localizada no ponto mais alto, a qual é fortalecida nos meses mais secos.

A primeira iniciativa que desencadeou o processo de planejamento estratégico do Plano de Manejo ocorreu em 2006, através do Workshop de Política de Conservação para as Unidades de Proteção Integral da Divisão de Florestas e Estações Experimentais (DFEE) do Instituto Florestal. Seguindo as recomendações do Roteiro Metodológico do IBAMA (2002) o planejamento ocorreu de forma flexível e participativa. O Plano de Manejo foi formulado no período de fevereiro de 2007 a fevereiro de 2009. Em 17 de Junho 2009, foi aprovado pelo Conselho Estadual do Meio Ambiente (CONSEMA). Sendo que em 21 de maio já havia sido deliberada a destinação de recursos para sua implantação, provenientes da compensação ambiental de uma usina beneficiadora de Açúcar.

Está previsto no Plano de Manejo a implementação de cinco Programas de Gestão: Programa de Administração e Operacionalização, Programa de Pesquisa e Monitoramento, Programa de Proteção, Programa de Educação Ambiental e Programa para o Desenvolvimento Sustentável. A implantação de Trilhas Interpretativas é uma das 
ações do Programa de Educação Ambiental da Unidade.

A Estação Ecológica de Angatuba é rica em recursos hídricos superficiais, o que proporciona atrativos para realização de programas de educação ambiental. As cachoeiras do Sargento e das Antas localizadas no curso d'água principal da microbacia do córrego do Sargento e pequenas quedas d'água nos riachos que drenam para esse córrego são exemplos de atrativos.

Também existem cinco trilhas que podem ser utilizadas por visitantes e pesquisadores: Trilha do Mirante $(1,38 \mathrm{~km})$, Trilha da Cachoeira do Sargento $(2,42$ $\mathrm{km})$, Trilha da Cachoeira das Antas $(1,25 \mathrm{~km})$, Trilha do Cortado $(1,43 \mathrm{~km})$, e Trilha Água Bonita $(2,05 \mathrm{~km})$ (MONTEIRO; PRADO, 2009).

\section{Metodologia}

Realizou-se um estudo prévio das possíveis trilhas que poderiam ser trabalhadas com a interpretação ambiental na zona de uso extensivo da Unidade. Optou-se por trabalhar com a trilha que possui maior distância, ligando o futuro centro de Educação Ambiental ao Mirante, e que atravessa trechos com recursos naturais e culturais significativos.

A seleção dos pontos interpretativos se deu de acordo com o Método IAPI (Indicadores de Atratividade de Pontos Interpretativos) proposto por Magro e Freixêdas (1998) que consiste em cinco fases:

Fase 1: Levantamento dos pontos potenciais para a interpretação

Os pontos potenciais para a interpretação foram selecionados em campo após uma prévia observação e estudo dos recursos naturais e culturais presentes na trilha em questão, em que se constatou que os temas: FAUNA, FLORA, ESPÉCIES AMEAÇADAS, ESPÉCIES EXÓTICAS E CULTURA CAIPIRA poderiam ser relevantes para a interpretação ambiental. Cada ponto pré-selecionado em campo foi registrado no GPS - Garmin MAP 60C e marcado com estacas cuja numeração era correspondente à do ponto no GPS.

\section{Fase 2: Levantamento e seleção de indicadores}

Realizou-se um levantamento em campo dos recursos naturais visíveis a partir dos pontos pré-selecionados na trilha para a escolha de alguns "indicadores de atratividade", que serviram como parâmetros de avaliação para a seleção dos Pontos Interpretativos e de descanso. Considerou-se na escolha dos Indicadores de Atratividade fatores como qualidade da experiência da visitação, facilidade de sua identificação em campo e possibilidade de repetição da avaliação pelo observador.

\section{Fase 3: Elaboração da Ficha de Campo}

Após a seleção dos Indicadores de Atratividade elaborou-se uma ficha de 
campo de modo a relacionar ausência ou presença destes elementos em cada um dos pontos pré-selecionados. Foram estabelecidos pesos para cada indicador, tendo como critério a importância de tal elemento na experiência do visitante na área.

\section{Fase 4: Uso da Ficha de Campo}

No campo utilizaram-se símbolos no preenchimento da ficha de campo para facilitar a identificação da intensidade dos recursos analisados no local, como $\mathrm{x}=$ presente; $x x x=$ predominância (vide Apêndice A). Por se tratar de uma análise subjetiva, foi precedida por um levantamento piloto com os observadores em conjunto, visando padronizar a atuação. Os pontos pré-selecionados foram analisados do início ao fim por uma mesma dupla para evitar mudanças de critérios.

A intensidade anotada para cada indicador foi transformada em valores numéricos para serem multiplicados pelo peso $(x=1 ; x x x=3)$.

\section{Fase 5: Seleção Final}

Os potenciais pontos interpretativos que obtiveram maior pontuação na ficha de campo foram selecionados para comporem o roteiro de interpretação ambiental da trilha. O mesmo procedimento foi utilizado na escolha do local para descanso ao longo da trilha.

A identificação das árvores foi realizada in loco pelo nome vulgar com o auxílio do funcionário da Estação Ecológica de Angatuba, Sr. Benedito Carlos de Oliveira, e posteriormente, com o material botânico coletado, confirmou-se o nome científico no herbário da Universidade Federal de São Carlos campus Sorocaba.

O traçado final da trilha foi estabelecido por meio da utilização de um software MapSource, o qual determinou a distância percorrida na trilha e a posição dos Pontos Interpretativos.

O esboço do roteiro de interpretação ambiental da trilha foi formulado considerando-se informações obtidas no campo e na literatura.

O design e conteúdo das placas de interpretação propostas foram elaborados de acordo com Vasconcellos (2006).

\section{Resultados e discussão}

\section{Seleção dos pontos da Trilha Interpretativa}

De acordo com o método IAPI (MAGRO; FREIXÊDAS,1998) foram selecionados 30 potenciais pontos para compor o Roteiro de Interpretação Ambiental. Foram estabelecidos sete Indicadores de Atratividade que serviram como parâmetros de avaliação para a seleção final dos Pontos Interpretativos (QUADRO 2). 
Planejamento de uma Trilha Interpretativa na Estação Ecológica de Angatuba (SP).

Quadro 2: Indicadores de Atratividade para seleção dos Pontos Interpretativos e de descanso.

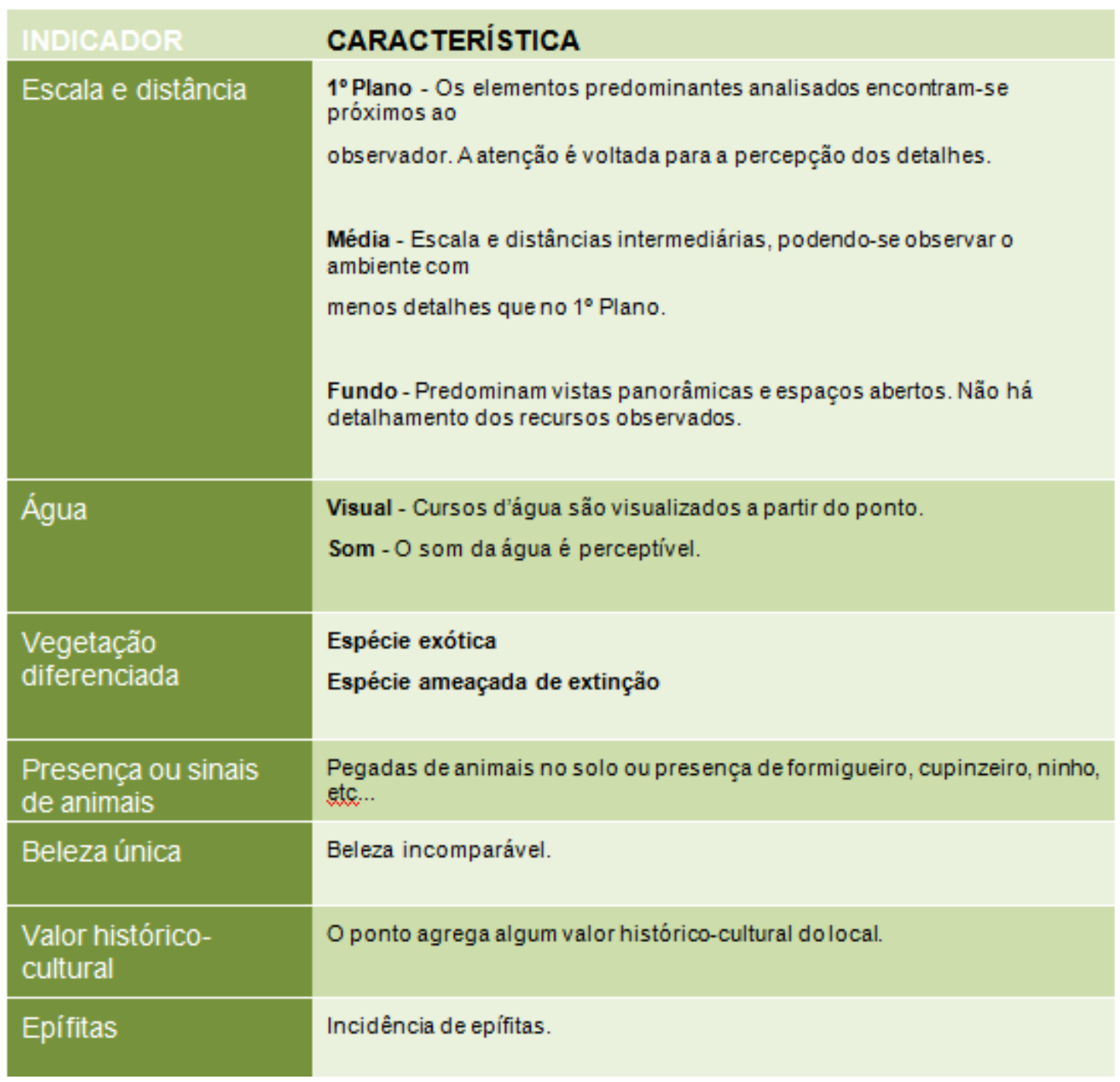

Fonte: dados de campo

Formulou-se a ficha de campo e posteriormente foram atribuídos pesos a cada indicador. Os indicadores escala - $1^{\circ}$ plano, água-som, vegetação diferenciada-espécie exótica, beleza única, valor histórico-cultural e epífitas receberam peso 2; enquanto que os indicadores escala-fundo, água-visual, vegetação diferenciada-espécie ameaçada e presença ou sinais de animais receberam peso 3 . Somente escala-média obteve peso 1. Para a determinação de tais pesos considerou-se os seguintes critérios:

Escala-1ํㅜ plano (peso 2): valorização dos detalhes;

Escala-média (peso 1): ausência de detalhes;

Escala-fundo (peso 3): valorização da paisagem, maior possibilidade de despertar os sentimentos e emoções do visitante; 
Água-visual (peso 3): sensação de bem-estar e maior contato com a natureza, maior possibilidade de despertar os sentimentos e emoções do visitante;

Água-som (peso 2): ambientação agradável, sensação de bem-estar;

Vegetação-diferenciada, espécie exótica (peso 2): problemática muito presente e discutida na conservação da natureza;

Vegetação-diferenciada, espécie ameaçada (peso 3): importância da conscientização e da informação e explicação de tal status;

Presença ou sinais de animais (peso 3): raridade e peculiaridade, maior possibilidade de despertar os sentimentos e emoções do visitante;

Beleza-única (peso 2): encantamento a primeira vista;

Valor-histórico cultural (peso 2): conhecimento da cultura local e dos fatos históricos;

Epífitas (peso 2): importância do conhecimento e identificação, sendo uma classificação não muito comum ao público leigo.

O preenchimento da ficha de campo seguiu os seguintes critérios: espaço em branco = ausente; $x=$ presente $; x x=$ predominância .

A intensidade anotada para cada indicador foi transformada em números $(x=1$; $x x x=3)$, os quais foram multiplicados pelo seu respectivo peso. Estes valores somados permitiram chegar a uma pontuação final para cada ponto (Ficha de campo).

Dentre os 30 pontos pré-selecionados foram selecionados na fase final 13 pontos, sendo onze Pontos Interpretativos e dois Pontos de Descanso (FIGURA 1 e QUADRO 3).

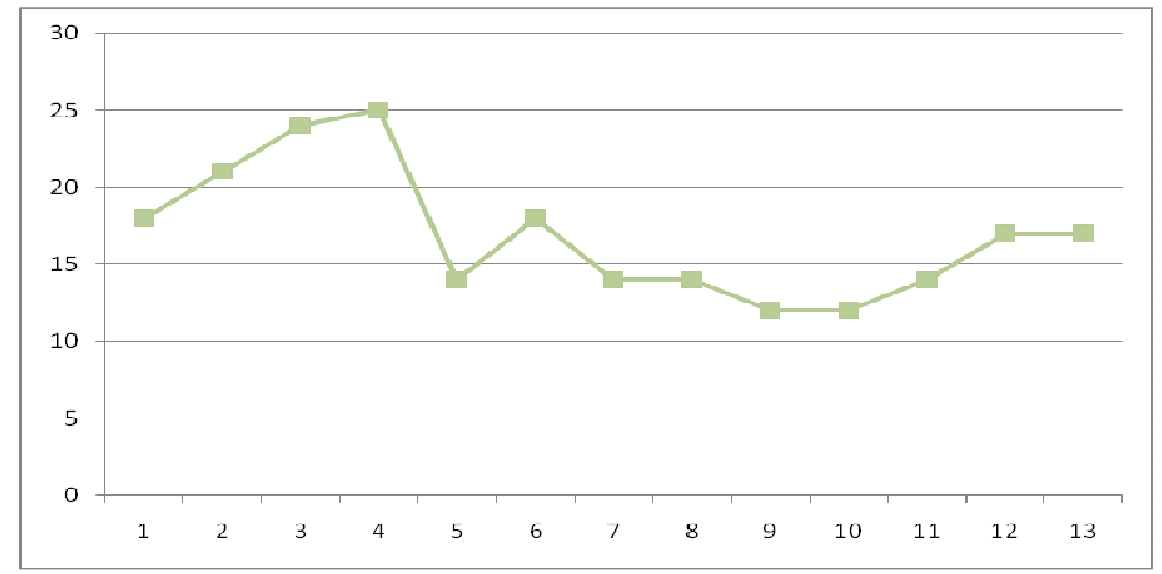

Figura 1: Valores finais de atratividade para os Pontos Interpretativos e Pontos de Descanso na trilha da Estação Ecológica de Angatuba. 
Planejamento de uma Trilha Interpretativa na Estação Ecológica de Angatuba (SP).

Quadro 3: pontos interpretativos e pontos de descanso selecionados. Fonte: dados de campo.

\begin{tabular}{|c|c|c|}
\hline NÚMERO & TEMA & CATEGORIA \\
\hline 1 & $\begin{array}{l}\text { Árvore Guaraperê - Lamanonia } \\
\text { ternata Vell. }\end{array}$ & Ponto interpretativo \\
\hline 2 & Trecho com pegadas de animais & Ponto interpretativo \\
\hline 3 & Lago & Ponto de descanso \\
\hline 4 & $\begin{array}{l}\text { Povoamento de Pinus sp.com } \\
\text { extração de resina }\end{array}$ & Ponto interpretativo \\
\hline 5 & Antiga casa da Fazenda & Ponto interpretativo \\
\hline 6 & Antigo viveiro & Ponto de descanso \\
\hline 7 & $\begin{array}{l}\text { Árvore Cambará - Gochnatia } \\
\text { polymorpha }\end{array}$ & Ponto interpretativo \\
\hline 8 & Árvore Eucalipto & Ponto interpretativo \\
\hline 9 & $\begin{array}{l}\text { Árvore Guaçatonga - Casearia } \\
\text { sylvestris }\end{array}$ & Ponto interpretativo \\
\hline 10 & $\begin{array}{l}\text { Arvora Canjarana - Cabralea } \\
\text { canjerana }\end{array}$ & Ponto interpretativo \\
\hline 11 & $\begin{array}{l}\text { Árvore Ipê-felpudo - Zeyheria } \\
\text { tuberculosa }\end{array}$ & Ponto interpretativo \\
\hline 12 & $\begin{array}{l}\text { Árvore Palmito Juçara - Euterpe } \\
\text { edulis }\end{array}$ & Ponto interpretativo \\
\hline 13 & $\begin{array}{l}\text { Árvore Araucária - Araucaria } \\
\text { angustifolia }\end{array}$ & Ponto interpretativo \\
\hline
\end{tabular}

A trilha interpretativa estudada (e traçada na Figura 2) possui aproximadamente uma distância de $2,0 \mathrm{Km}$ e compreende uma área pertencente à Floresta Estadual de Angatuba, sendo que esta é contígua à Estação Ecológica de Angatuba. Por conta disso, há a presença de espécies exóticas como Pinus, com extração de resina, e Eucalipto. Dentro da área da Estação Ecológica a trilha interpretativa está localizada na Zona de Uso Extensivo, a qual permite a implementação de trilhas, de acordo com Zoneamento da Unidade.

De acordo com a classificação de trilhas de Andrade e Rocha (2008), a trilha estudada foi classificada da seguinte maneira:

Quanto à função: Trilha de Curta Distância, chamada de trilha de interpretação (natural trails) guiada, de acordo com as normas do programa de Educação Ambiental;

Quanto à forma: Trilha Atalho;

Grau de dificuldade: A-2. 
Garcia, F.O.; Neiman, Z.; Prado, B.H.S.






\section{Placas de Interpretação}

De acordo com Vasconcellos (2006), as placas devem ser planejadas para serem atrativas e compreendidas por diversos públicos, além de ser uma forma de comunicação rápida. Seguindo o que estabelece a autora, as placas foram planejadas para serem atrativas, breves e claras.

Foram planejadas três placas para serem colocadas no percurso da trilha interpretativa da Estação Ecológica de Angatuba, sendo uma Placa Informativa (Figura 3) e duas Placas Interpretativas (Figuras 4 e 5). De acordo com Vasconcellos (2006) recomenda-se que a fonte seja Bodini MT; o tamanho da letra seja de $1,25 \mathrm{~cm}$, já que a distância da leitura é de aproximadamente $1,3 \mathrm{~m}$; e que sejam confeccionadas com material resistente às condições ambientais do local, para maximizar a durabilidade da placa.

Embora o recurso visual de placas seja mais comumente usado em trilhas autoguiadas, optou-se por utilizar tal recurso na trilha interpretativa guiada por se considerar a importância desse recurso na interpretação ambiental.

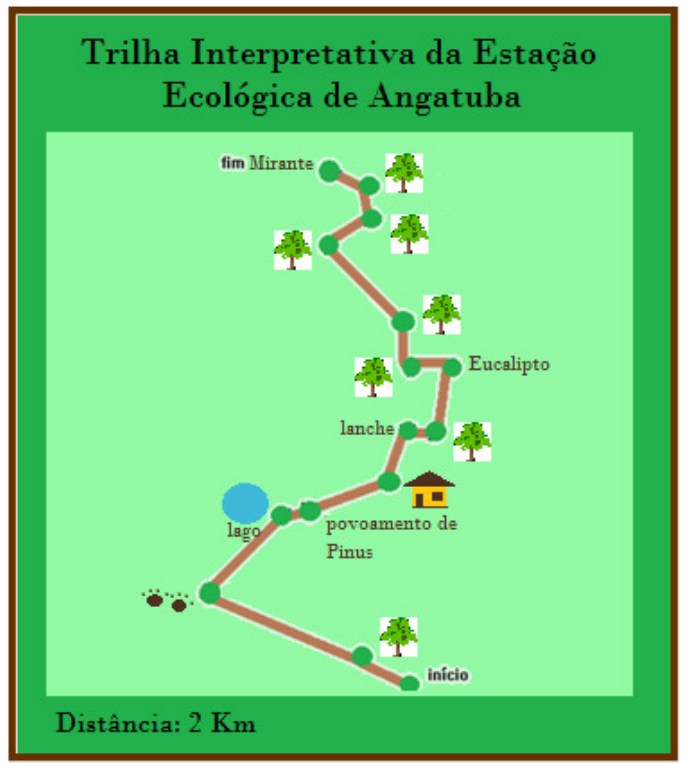

Figura 3: Placa de Informativa a ser colocada no início da trilha interpretativa.

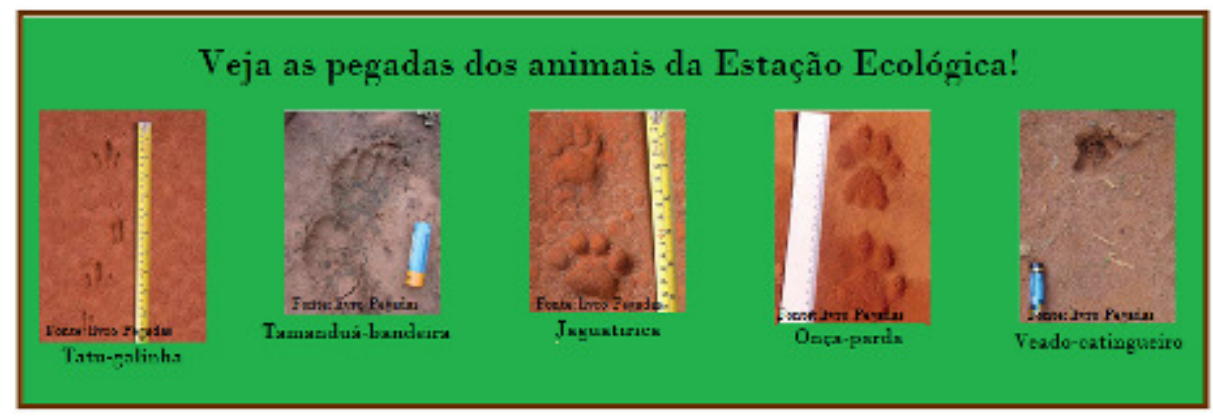

Figura 4: Placa Interpretativa a ser colocada no ponto 2 da trilha interpretativa 




Figura 5: Placa Interpretativa a ser colocada no ponto 5 da trilha interpretativa.

\section{Esboço do Roteiro Interpretativo}

O esboço do roteiro interpretativo (Quadro 4, na página seguinte) será desenvolvido de forma participativa nas oficinas de Educação Ambiental que serão realizadas de acordo com o Programa de Educação Ambiental, assim como também - nome da trilha interpretativa estudada. Nessas oficinas pretende-se reunir a comunidade do entorno da Unidade, corpo técnico das áreas afins e demais interessados.

\section{Conclusão}

A trilha interpretativa planejada possui aproximadamente $2,0 \mathrm{~km}$ de distância, é classificada como Trilha de Interpretação guiada, Atalho e grau de dificuldade A-2, conforme Andrade e Rocha (2008). Possui 13 pontos de Interpretação Ambiental, sendo dois pontos para descanso. Os pontos compreendem aspectos da flora, fauna, histórico-culturais e de desenvolvimento sustentável.

O esboço do Roteiro Interpretativo foi elaborado de forma a considerar as possibilidades de abordagem dos temas selecionados. Dessa forma, acredita-se que esse será desenvolvido de maneira satisfatória nas oficinas de Educação Ambiental, sendo que os participantes poderão sugerir novas abordagens e métodos de acordo com seus conhecimentos e experiências sobre o assunto. Assim, o roteiro poderá ser sempre reajustado conforme o público-alvo da visita e o acréscimo de novas ideias. 
As placas propostas abordam aspectos peculiares do local e têm a intenção de despertar os sentimentos dos visitantes quanto aos determinados aspectos de que tratam. Acredita-se que essa ferramenta visual facilite a incorporação da mensagem que a trilha interpretativa pretende passar.

Como trabalho futuro, sugere-se o estudo da capacidade de suporte da trilha interpretativa para que haja o mínimo impacto.

Quadro 4: Esboço do Roteiro Interpretativo da Estação Ecológica de Angatuba.

\begin{tabular}{|c|c|}
\hline TEMA & $\begin{array}{c}\text { FATORES A SEREM ABORDADOS } \\
\text { (Detalhamento do conteúdo sugerido pode ser encontrado no apêndice B). }\end{array}$ \\
\hline Início da trilha & $\begin{array}{l}\text { - mostrar croqui da trilha e as recomendações para fazê-la, como não } \\
\text { sair da trilha, manter-se em silêncio, não fazer coleta, não jogar lixo, } \\
\text { não alterar nada do local. } \\
\text { - comentar o percurso da trilha que atravessa formações vegetacionais } \\
\text { de cerrado e Floresta Estacional Semidecidual, e passa pela Floresta } \\
\text { Estadual de Angatuba antes de entrar propriamente na área de Estação } \\
\text { Ecológica. } \\
\text { - chamar a atenção para que procurem as pegadas dos animais. } \\
\text { - convidar os visitantes a ver, ouvir e sentir a natureza. }\end{array}$ \\
\hline $\begin{array}{l}\text { Árvore Guaraperê - } \\
\text { Lamanonia ternata } \\
\text { Vell. }\end{array}$ & $\begin{array}{l}\text { - falar sobre as características e peculiaridades da espécie. } \\
\text { - explorar exsicatas, casco, frutos e sementes e epífitas. }\end{array}$ \\
\hline $\begin{array}{l}\text { Trecho com pegadas } \\
\text { de animais }\end{array}$ & $\begin{array}{l}\text { Pegadas comumente encontradas: } \\
\text { - veado-catingueiro, } \\
\text { - gato-do-mato (vulnerável). } \\
\text { - tatu-galinha, } \\
\text { - tamanduá-bandeira (vulnerável e endêmico do cerrado), } \\
\text { - explorar a fauna que ocorre no local. }\end{array}$ \\
\hline Lago & Ponto de descanso \\
\hline $\begin{array}{l}\text { Antiga casa da } \\
\text { Fazenda }\end{array}$ & $\begin{array}{l}\text { - explicar que tal casa é da época da antiga fazenda particular, } \\
\text { chamada de Fazenda da Conquista pertencente a família Vieira de } \\
\text { Moraes, e que em } 1965 \text { a fazenda foi comprada pelo Governo do } \\
\text { Estado de São Paulo, onde foi criada a Floresta Estadual de Angatuba } \\
\text { e somente em } 1985 \text { foi criada a Estação Ecológica de Angatuba nas } \\
\text { áreas que não foram utilizadas para o reflorestamento pela Floresta } \\
\text { Estadual de Angatuba. } \\
\text { - explorar as tradições da cultura caipira. }\end{array}$ \\
\hline Antigo viveiro & Ponto de descanso - lanche \\
\hline
\end{tabular}

Continua... 
...Continuação.

\begin{tabular}{|c|c|}
\hline $\begin{array}{l}\text { Árvore Cambará - } \\
\text { Gochnatia polymorpha }\end{array}$ & $\begin{array}{l}\text { - falar sobre as características e peculiaridades da espécie. } \\
\text { - explorar exsicatas, casco, frutos e sementes e epífitas. }\end{array}$ \\
\hline Árvore Eucalipto & $\begin{array}{l}\text { - explicar que tal espécie é exótica e tida como invasora, e por conta } \\
\text { disso não deveria existir em uma Unidade de Conservação de } \\
\text { Proteção Integral; o motivo histórico de existir essa espécie no local; } \\
\text { o que está sendo feito para combater essa espécie. }\end{array}$ \\
\hline $\begin{array}{l}\text { Árvore Guaçatonga - } \\
\text { Casearia sylvestris }\end{array}$ & $\begin{array}{l}\text { - falar sobre as características e peculiaridades da espécie. } \\
\text { - explorar exsicatas, casco, frutos e sementes e epífitas. }\end{array}$ \\
\hline $\begin{array}{l}\text { Arvora Canjarana - } \\
\text { Cabralea canjerana }\end{array}$ & $\begin{array}{l}\text { - falar sobre as características e peculiaridades da espécie. } \\
\text { - explorar exsicatas, casco, frutos e sementes e epífitas. }\end{array}$ \\
\hline $\begin{array}{l}\text { Árvore Ipê-felpudo - } \\
\text { Zeyheria tuberculosa }\end{array}$ & $\begin{array}{l}\text { - falar sobre as características e peculiaridades da espécie. } \\
\text { - explorar exsicatas, casco, frutos e sementes e epífitas. }\end{array}$ \\
\hline $\begin{array}{l}\text { Árvore Palmito Juçara - } \\
\text { Euterpe edulis }\end{array}$ & $\begin{array}{l}\text { - falar que tal espécie é tida como vulnerável no estado de São } \\
\text { Paulo e em extinção no Brasil, e sobre as características e } \\
\text { peculiaridades da espécie } \\
\text { - explicar o motivo de ter sido tão explorada. } \\
\text { - salientar a importância de se consumir palmito com selo expedido } \\
\text { por órgão responsável. }\end{array}$ \\
\hline $\begin{array}{l}\text { Árvore Araucária - } \\
\text { Araucaria angustifolia }\end{array}$ & $\begin{array}{l}\text { - falar que tal espécie é exótica e está ameaçada de extinção em seu } \\
\text { local de ocorrência natural; o motivo histórico de existir essa espécie } \\
\text { no local; e sobre as características e peculiaridades da espécie. }\end{array}$ \\
\hline Mirante - fim da trilha & $\begin{array}{l}\text { - realizar uma síntese de tudo que explorado no percurso da trilha, } \\
\text { passando aos visitantes a importância de se ter a área protegida, } \\
\text { principalmente por abrigar espécies da fauna e flora que estão } \\
\text { ameaçados de extinção e aspectos da cultura caipira. } \\
\text { - ressaltar que ali é o habitat de muitos animais, e que como em } \\
\text { nossa casa, precisa haver alimento, abrigo e paz para ser um } \\
\text { ambiente harmonioso. } \\
\text { - despertar o pensamento dos visitantes em relação à situação em } \\
\text { que poderia estar a área senão fosse legalmente protegida. Será } \\
\text { que teria virado pasto? Plantação agrícola? Condomínio ou } \\
\text { loteamento de casas? E como e onde estariam os animais que ali } \\
\text { vivem? } \\
\text { - mostrar que pode haver a conciliação entre preservação e } \\
\text { conservação, como ali se faz com a Estação Ecológica e Floresta } \\
\text { Estadual. } \\
\text { - motivar os visitantes para que eles sejam agentes multiplicadores } \\
\text { da conscientização da proteção da natureza. }\end{array}$ \\
\hline
\end{tabular}

Fonte: dados de campo. 


\section{Referências Bibliográficas}

ANDRADE, W. J.; ROCHA ,R. F. da. Manejo de trilhas: um manual para gestores. São Paulo, 2008. 35 n. Série Registros. Governo do Estado de São Paulo: Secretaria do Meio Ambiente: Instituto Florestal.

ARAÚJO, M. A. R. Unidades de conservação no Brasil: da república à gestão de classe mundial. Belo Horizonte: Segrac, 2007. 6 cap.

BRASIL. Lei no 9.985, de 18 de julho de 2000. Regulamenta o art. 225, § 10, incisos I, II, III e VII da Constituição Federal, institui o Sistema Nacional de Unidades de Conservação da Natureza e dá outras providências. Publicado no Diário Oficial da União de 19 de julho de 2000.

CARVALHO, P. E. R. Espécies Arbóreas Brasileiras. Brasília: Embrapa Informação Tecnológica; Colombo, PR: Embrapa Florestas, 2003. 1. vol.

CHAGAS, K. K. N. Educação ambiental: o papel da sensibilidade em trilhas ecológicas. In: ENCONTRO NACIONAL DE RECREAÇÃO E LAZER: lazer no espaço urbano: transversalidade e novas tecnologias, 18., 2006, Curitiba. Anais...Curitiba, 2006.

GUIMARÃES, S. T. de L. Paisagens: aprendizados mediante experiências. Um ensaio sobre interpretação e valoração da paisagem. Rio Claro, 2007. 167 f. Tese (livredocência) - Instituto de Geociências e Ciências Exatas, Universidade Estadual Paulista.

GUIMARÃES, S. T. de L. Trilhas interpretativas e vivências na natureza: reconhecendo e reencontrando nossos elos com a paisagem. Cadernos Paisagem, Rio Claro, n. 3, p. 3944, 1998.

JUNIOR, O. C.; LUZ, N. C. Pegadas. Belém: EDUFPA, 2008. 3 vol.

LORENZI, H. Árvores brasileiras: Manual de identificação e Cultivo de Plantas Arbóreas Nativas do Brasil. 5. ed. Nova Odessa, SP: Instituto Plantarum, 2008. 1 vol.

MAGRO, T.; FREIXÊDAS, V. Trilhas: como facilitar a seleção de pontos Interpretativos. São Paulo, ESALQ/USP, 1998. Disponível em: < http://www.infotrilhas.com/Downloads/ trilha.pdf>. Acesso em: 25 ago. 2010.

MONTEIRO, C. H. B; PRADO, B. H. S. do; DIAS, A. C. (coords.). Plano de Manejo: Estação Ecológica de Angatuba. São Paulo: Instituto Florestal, 2009. CD-ROOM.

Plano de Trabalho objeto da aplicação de recursos de compensação ambiental: Estação Ecológica de Angatuba. São Paulo: Instituto Florestal, 2009. CDROOM.

NEIMAN, Z.; LEITE, E. C.; PODADERA, D.S. Planejamento e implantação participativos de programas de interpretação em trilhas na "RPPN Paiol Maria", Vale do Ribeira - SP. Revista Brasileira de Ecoturismo, São Paulo, v. 2, n. 1, p. 11-34, 2009.

NEIMAN, Z.; RABINOVICI, A. Envolvimento Sustentável em Comunidades de Conservação. OLAM - Ciência \& Tecnologia, Rio Claro, v. 8, n. 2, p. 6-30, jun. 2008. 
OLIVEIRA, L. R. N. de (org). Unidades de conservação da natureza. São Paulo, 2009. 3 n. Cadernos de Educação Ambiental. Governo do Estado de São Paulo: Secretaria do Meio Ambiente: Fundação Florestal.

SANTOS, C. G. dos. Educação Ambiental e ecologismo nas trilhas das caminhadas Ecológicas. Niterói, 2007. 126 f. Dissertação (Mestrado em Ciência Ambientais) - Instituto de Geociências, Universidade Federal Fluminense.

SENICIATO, T.; CAVASSAN, O. Aulas de Campo em Ambientes Naturais e Aprendizagem em Ciências - Um Estudo com Alunos do Ensino Fundamental. Ciência \& Educação, São Paulo, v. 10, n. 1, p. 133-147, 2004.

SOARES, F. J. Caminhos para o desenvolvimento da sensibilidade ambiental: uma incursão sobre as evidências. Projeto - Revista de Educação, Porto Alegre, v. 6, n. 8, p. 5-9, 2004.

TROPICOS. Disponível em: <http://www.tropicos.org>. Acesso em: 9 de mar. 2011.

VASCONCELLOS, J. M. O. Educação e Interpretação Ambiental em Unidades de Conservação. Curitiba, 2006. 4 n. Fundação O Boticário de Proteção à Natureza. Cadernos de Conservação.

ZANIN, E. M. Projeto trilhas interpretativas - a extensão, o ensino e a pesquisa integrados à conservação ambiental e à educação.Vivências, v.1, n. 2, p. 26-35, mai. 2006.

Francini de Oliveira Garcia: Universidade Federal de São Carlos

Email: franciniogarcia@gmail.com

Zysman Neiman: Universidade Federal de São Carlos

Email: zysman@ufscar,br

Link para currículo Lattes: http://lattes.cnpq.br/6435341856481082

Bárbara Heliodora Soares do Prado: Instituto Florestal

Email: barbara@if.sp.gov.br

Data de submissão: 28 de maio de 2011.

Data do aceite: 03 de setembro de 2011. 
Planejamento de uma Trilha Interpretativa na Estação Ecológica de Angatuba (SP).

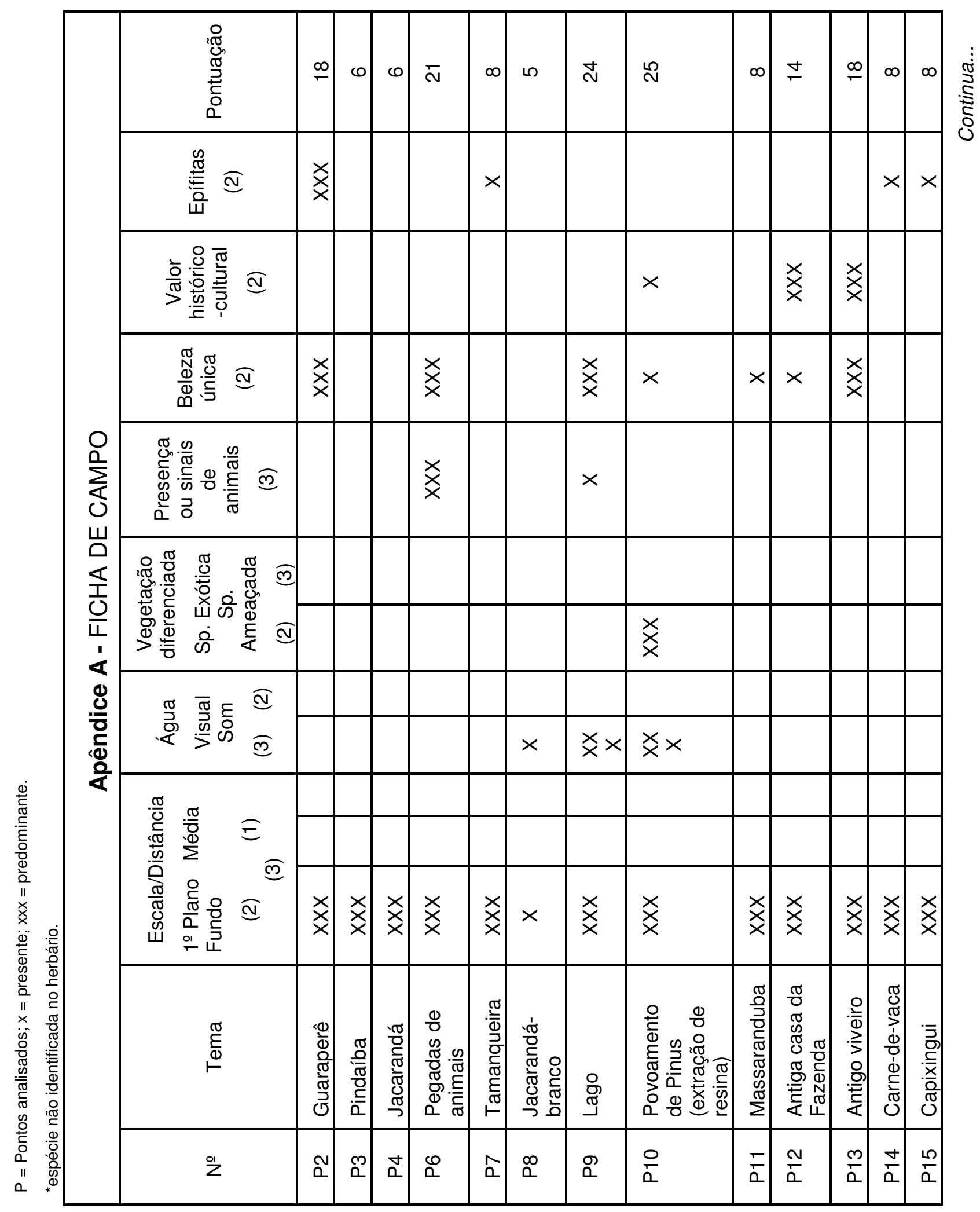

Página 342

Revista Brasileira de Ecoturismo, São Paulo, v.4, n.3, $201 \mathrm{l}$. 
Garcia, F.O.; Neiman, Z.; Prado, B.H.S.

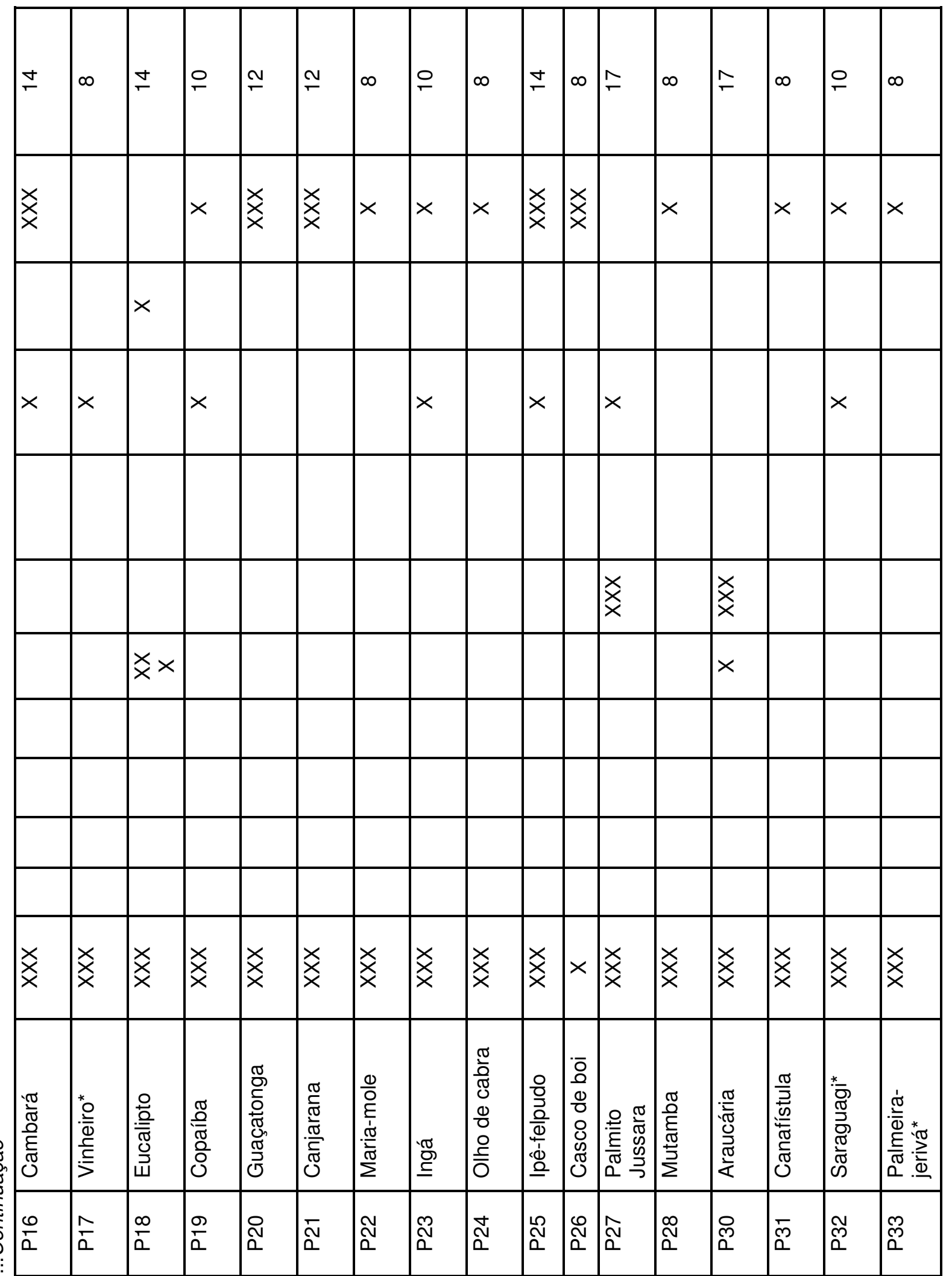

Página 343

Revista Brasileira de Ecoturismo, São Paulo, v.4, n.3, 2011. 


\begin{tabular}{|c|c|}
\hline \multicolumn{2}{|c|}{$\begin{array}{l}\text { Apêndice B - Sugestão de conteúdo a ser trabalhado com as espécies arbóreas nativas, segundo Lorenzi (2008) e } \\
\text { Carvalho (2003). }\end{array}$} \\
\hline $\begin{array}{l}\text { Árvore Guaraperê - } \\
\text { Lamanonia ternata Vell. }\end{array}$ & $\begin{array}{l}\text { - apresenta característica ornamental, principalmente quando em flor. } \\
\text { - fornecedora de ótima sombra. } \\
\text { - adaptação à terrenos secos e tolerante à insolação direta. } \\
\text { - útil em plantios heterogêneos em áreas degradadas. } \\
\text { - floresce nos meses de outubro-dezembro. } \\
\text { - maturação dos frutos no período de junho-agosto. } \\
\text { - flores melíferas. } \\
\text { - o casco do caule, quando usada na forma de banhos e compressas, é adstringente e indicada na } \\
\text { cura de feridas ou úlceras externas. }\end{array}$ \\
\hline $\begin{array}{l}\text { Árvore Cambará - } \\
\text { Gochnatia polymorpha }\end{array}$ & $\begin{array}{l}\text { - pioneira adaptada à terrenos pobres e secos. } \\
\text { - própria para reflorestamentos mistos de áreas degradadas. } \\
\text { - floresce nos meses de outubro-dezembro. } \\
\text { - maturação dos frutos no período de dezembro-fevereiro. } \\
\text { - apresenta características ornamentais, principalmente pela cor prateada de sua folha e a forma } \\
\text { retorcida dos ramos. } \\
\text { - flores melíferas com produção de néctar. } \\
\text { - folhas utilizadas na medicina popular no tratamento das afecções bronco-pulmonares, } \\
\text { expectorante e emoliente. }\end{array}$ \\
\hline $\begin{array}{l}\text { Árvore Guaçatonga - } \\
\text { Casearia sylvestris }\end{array}$ & $\begin{array}{l}\text { - folhas são reputadas como medicinais. } \\
\text { - árvore de porte elegante e pequeno é ideal para arborização de ruas estreitas sob redes elétricas. } \\
\text { - frutos avidamente consumidos por várias espécies de pássaros. } \\
\text { - pioneira e rústica. } \\
\text { - indispensável em plantios mistos destinados ao repovoamento de áreas degradadas. } \\
\text { - floresce nos meses de junho-agosto. } \\
\text { - maturação dos frutos no período de setembro-novembro. }\end{array}$ \\
\hline $\begin{array}{l}\text { Arvora Canjarana - } \\
\text { Cabralea canjerana }\end{array}$ & $\begin{array}{l}\text { - arilo suculento que envolve a semente é consumido por várias espécies de pássaros. } \\
\text { - indispensável na composição de reflorestamento heterogêneos de áreas destinadas à } \\
\text { preservação. } \\
\text { - floresce em mais de uma época por ano, com maior intensidade nos meses de setembro-outubro. } \\
\text { - maturação dos frutos também se dá em mais de uma época por ano, com maior intensidade no } \\
\text { período de agosto-novembro. } \\
\text { - o suco dos frutos têm ação inseticida, devendo ser tóxico aos animais. } \\
\text { - extrai-se da casca um corante vermelho utilizado na indústria de tinturaria. } \\
\text { - perfume extraído das folhas é usado na indústria de perfumaria. } \\
\text { - flores melíferas com produção de néctar e pólen. } \\
\text { - é utilizada na medicina popular como poderoso reconstituinte nos estados anêmicos. Suco leitoso } \\
\text { da casca usado como chá para combater doenças de pele, diarreias, prisão de ventre, febres e } \\
\text { hidropisia. O decocto da raiz é tido como purgativo, antidispéptico, antitérmico, adstringente, } \\
\text { emético e arbotivo. Folhas com propriedades antitérmicas. Chá da casca é adstringente, fortificante } \\
\text { na convalescença, muito utilizado no combate de disenterias e artrites. O uso externo da casca } \\
\text { fervida pode ser aplicado em feridas e inflamação dos testículos. A casca cozida serve para } \\
\text { combater dispepsias, febres, prisão de ventre, diarreias, hidropsia e afecções de pele. }\end{array}$ \\
\hline $\begin{array}{l}\text { Árvore Ipê-felpudo - } \\
\text { Zeyheria tuberculosa }\end{array}$ & $\begin{array}{l}\text { - ornamental pela elegância de sua copa. } \\
\text { - facilidade de multiplicação e rapidez de crescimento. } \\
\text { - indispensável nos reflorestamentos heterogêneos destinados à recomposição de áreas } \\
\text { degradadas. } \\
\text { - floresce nos meses de novembro-janeiro. } \\
\text { - maturação dos frutos no período de julho-setembro. } \\
\text { - flores melíferas. } \\
\text { - do fruto são feitos trabalhos de artesanatos. }\end{array}$ \\
\hline $\begin{array}{l}\text { Árvore Palmito Juçara - } \\
\text { Euterpe edulis }\end{array}$ & $\begin{array}{l}\text { - folhas servem para ração animal. } \\
\text { - sementes podem ser usadas em ração ou adubo. } \\
\text { - fornece palmito comestível. } \\
\text { - parte comestível do palmito é a parte compreendida entre o ápice da palmeira e o lugar de } \\
\text { inserção da inflorescência. As bainhas também são utilizadas em pastas, sopas e molhos, assim } \\
\text { como os botões florais em doces e para decorar a dar gosto a saladas. } \\
\text { - flores melíferas com produção de pólen abundante. } \\
\text { - folhas são usadas em artesanato, na confecção de cadeiras de palha. }\end{array}$ \\
\hline $\begin{array}{l}\text { Árvore Araucária - } \\
\text { Araucaria angustifolia }\end{array}$ & - semente "pinhão" comestível e avidamente consumida por várias espécies da fauna. \\
\hline
\end{tabular}

Página 344

Revista Brasileira de Ecoturismo, São Paulo, v.4, n.3, 2011. 